\title{
SEROGROUP DIVERSITY AND ANTIBIOTIC SUSCEPTIBILITY OF NEISSERIA MENINGITIDIS: MENINGOCOCCUS INFECTION MONITORING IN BELARUS
}

\author{
HANNA N. KHARKHAL* and LEONID P. TITOV \\ Laboratory of Clinical and Experimental Microbiology, The Republican Research and \\ Practical Center for Epidemiology and Microbiology, Minsk, Republic of Belarus
}

(Received: 8 March 2019; accepted: 23 April 2019)

\begin{abstract}
This study performed an epidemiological survey of Neisseria meningitidis strains isolated from patients and from asymptomatic carriers. Altogether, 74 $N$. meningitidis strains (46 invasive and 28 non-invasive) were isolated between February 2011 and May 2018 in different regions of the Republic of Belarus. Serogenotyping was carried out by real-time PCR. Minimum inhibitory concentrations (MICs) of antibiotics were determined by broth microdilution and results were interpreted in accordance with EUCAST. The serogroups of $N$. meningitidis were determined as follows: serogroup B $-65 \%, \mathrm{C}-11 \%, \mathrm{~W}-9 \%, \mathrm{~A}-5 \%, \mathrm{Y}-4 \%$, and $\mathrm{Z}$ and $\mathrm{NG}-3 \%$ each. The $\mathrm{MIC}_{50}$ and $\mathrm{MIC}_{90}$ for benzylpenicillin $(0.032 / 0.064$ $0.125 \mathrm{mg} / \mathrm{L})$, ampicillin $(0.032 / 0.125 \mathrm{mg} / \mathrm{L})$, amoxicillin $(0.125 / 0.25 \mathrm{mg} / \mathrm{L})$, cefotaxime $(0.016 / 0.016 \mathrm{mg} / \mathrm{L})$, ceftriaxone $(0.002 / 0.016 \mathrm{mg} / \mathrm{L})$, ciprofloxacin $(0.004 /$ $0.008 \mathrm{mg} / \mathrm{L})$, chloramphenicol $(1 / 1 \mathrm{mg} / \mathrm{L})$, meropenem $(0.008 / 0.008-0.016 \mathrm{mg} / \mathrm{L})$, tetracycline $(0.25 / 0.5 \mathrm{mg} / \mathrm{L})$, and rifampicin $(0.016 / 0.25 \mathrm{mg} / \mathrm{L})$ were established. Strains with intermediate susceptibility for benzylpenicillin (12.3\%), ampicillin (6.8\%), and amoxicillin (24.7\%) have been identified. In this study, we report the first rifampicinresistant $N$. meningitidis in Belarus.
\end{abstract}

Keywords: antibiotics, surveillance, meningococcal infection, resistance

\section{Introduction}

Meningococcal infection is still an urgent problem of the practical public health in the Republic of Belarus [1]. According to the Republican Center for Hygiene, Epidemiology and Public Health data, the notification rate of meningococcal infection in 2016 was 0.591 per 100 thousand populations, in 2017, it was 0.665 per 100 thousand populations, and for the period from January 1 to July 31 ,

\footnotetext{
*Corresponding author; E-mail: anna-madlen69@yandex.ru
} 
2018, it was 0.443 per 100 thousand populations. The mortality rate of patients with generalized forms of meningococcal infection remains quite high as in 2016 and 2017; altogether, eight cases were registered that indicates $15 \%$ mortality rate.

Due to the low incidence of meningococcal disease in the Republic of Belarus, vaccination against it is not provided in the National Vaccination Calendar. However, because of increase of migration and traveling to countries with a high incidence of meningococcal infections, the meningococcal group B vaccine (recombinant and adsorbed) "Trumenba" (Pfizer HCP Corporation, USA/Pfizer Ireland Pharmaceuticals, Ireland) was registered in the Republic of Belarus in 2018. Vaccine delivery to health care facilities is scheduled for 2019 and will be available for fee.

On the basis of Laboratory of Clinical and Experimental Microbiology (reference laboratory) at the Republican Research and Practical Center for Epidemiology and Microbiology (Minsk, Belarus), the microbiological invasive bacterial diseases (IBD) surveillance (caused by Streptococcus pneumoniae, Neisseria meningitidis, and Haemophilus influenzae) (Ministry of Health order no. 1102 from September 20,2012) [2,3] and meningococcal infection surveillance (Figure 1) are held.

Rational antibiotic therapy and chemoprophylaxis allow to prevent complications in patients with meningococcal infection, as well as to reduce the transmission of $N$. meningitidis among carriers. $N$. meningitidis is sensitive to most antibiotics, but in recent years, the frequency of isolates with intermediate sensitive and

\begin{tabular}{|c|c|c|c|}
\hline \multicolumn{4}{|c|}{ MINISTRY OF HEALTH } \\
\hline information & & & \\
\hline REPUBLICAN CE & FOR HYGIENE, & DDEMIOL & AND PUBLIC HEALTH \\
\hline I information & & biomaterial & information \\
\hline HOSPITALS & LABORATORIES & & REFERENCE-LABORATORY \\
\hline $\begin{array}{l}\text { Cases suspicious for } \\
\text { meningococcal } \\
\text { infection detection; } \\
\text { Blood, cerebrospinal } \\
\text { fluid and/or } \\
\text { nasopharyngeal swab } \\
\text { collection; } \\
\text { - Biomaterial transfer } \\
\text { to laboratory for } \\
\text { bacteriological } \\
\text { researches; } \\
\text { - Biomaterial transfer } \\
\text { to reference- } \\
\text { laboratory for PCR; } \\
\text { - Case reports. }\end{array}$ & $\begin{array}{l}\text { Bacteriological } \\
\text { seeding of } \\
\text { biomaterial; } \\
\text { - Bacterial } \\
\text { identification; } \\
\text { - N.meningitidis } \\
\text { serotyping; } \\
\text { - N.meningitidis } \\
\text { antimicrobial } \\
\text { susceptibility testing; } \\
\text { - Retum of results to } \\
\text { the hospital; } \\
\text { - N.meningitidis strains } \\
\text { transfer to reference- } \\
\text { laboratory. }\end{array}$ & information & $\begin{array}{l}\text { N.meningitidis gene detection in biomaterial by } \\
\text { RT-PCR method; } \\
\text { - N.meningitidis strains reidentification; } \\
\text { - N.meningitidis isolates from biomaterial and } \\
\text { N.meningitidis strains from hospitals and } \\
\text { laboratories serogenotyping by PCR method; } \\
\text { - N.meningitidis multi-locus sequence typing } \\
\text { (MIST); } \\
\text { - Antibiotics MICs detection; } \\
\text { - Depositing into the Specialized Collection of } \\
\text { viruses and bacteria pathogenic for humans and } \\
\text { animals (RRPC for epidemiology and } \\
\text { microbiology) of N.meningitidis strains; } \\
\text { - Scientific reports, articles; } \\
\text { Conferences, workshops. }\end{array}$ \\
\hline
\end{tabular}

Figure 1. Meningococcal infection surveillance in the Republic of Belarus 
resistance has increased in European countries [4-7], America [7-10], Australia [7, 11], and Asia [12]. Strains with reduced susceptibility to penicillins and chloramphenicol that circulated in Belarus were previously described [13].

The aim of this study was to determine the phenotypic susceptibility to antibiotics of $N$. meningitidis strains isolated in Belarussian hospitals and transferred to Republican reference laboratory for the diagnosis of IBD (Laboratory of Clinical and Experimental Microbiology of Republican Research Center for Epidemiology and Microbiology) in 2011-2018.

Antibiotics for this study were selected according to clinical protocols for the diagnosis and treatment of infectious diseases in adults and children (Ministry of Health order no. 484 from June 13, 2006, Appendix 5 [14] and order no. 961 from August 24, 2012 [15], respectively). Antibiotics, which are prescribed for meningococcal infections treatment, are benzylpenicillin, chloramphenicol, ceftriaxone, and meropenem; for N. meningitidis elimination in carriers, antibiotics such as rifampicin and ciprofloxacin are used; antibiotics widely used for threatening different infection forms are ampicillin, amoxicillin, cefotaxime, and tetracycline.

\section{Materials and Methods}

Altogether, $74 N$. meningitidis strains (46 invasive and 28 non-invasive) were isolated during February 2011-May 2018 from different regions of the Republic of Belarus: Minsk - 47.3\% (20 invasive/15 non-invasive), Brest region - 14,7\% (9/2), Mogilev region $-12.2 \%(4 / 5)$, Grodno region $-10.8 \%$ (6/2), Vitebsk region $-9.5 \%$ (5/2), Minsk region $-4.1 \%$ (2/1), and Gomel region - 1.4\% (1 non-invasive).

Invasive strains were isolated from patients aged from 3 months to 62 years (average- 8.9 years, interquartile range of 9 months -14 years); female $-52 \%$, male $48 \%$. About $65.2 \%$ patients had meningococcemia [21 strains from cerebrospinal fluid (CSF) samples and 9 from blood] and $34.8 \%$ had meningitis (14 strains from CSF samples and 2 from blood).

Non-invasive strains were isolated from nasopharyngeal swabs of 28 carriers, who contacted patients with meningococcal invasive infection, aged from 5 months to 59 years (average -26.7 years, interquartile range of 3-48 years); female $-44 \%$, male $-56 \%$.

\section{Laboratory diagnosis}

Bacterial cultivation was carried out using GC-agar (Conda, Spain) with $20 \%$ horse serum addition (Himmedsintez, Republic of Belarus, Minsk) and commercial supplement VCNT (HiMedia, India) in a $\mathrm{CO}_{2}$ incubator at $37^{\circ} \mathrm{C}$ and $5 \%-10 \% \mathrm{CO}_{2}$ for $20-24 \mathrm{~h}$. 
Additional molecular reidentification was carried out by RT-PCR with superoxide dismutaseC ( $\operatorname{sod} C)$ gene detection according to WHO and CDC (Atlanta, USA) recommendations [16]. RT-PCR was held on Rotor-gene 3000 (Corbett Research, Australia) with running parameters: one cycle on $95{ }^{\circ} \mathrm{C}$ for $10 \mathrm{~min}$, then 45 cycles on $95^{\circ} \mathrm{C}$ for $15 \mathrm{~s}$, and on $60^{\circ} \mathrm{C}$ for $60 \mathrm{~s}$ with fluorescence detection on 6-carboxyfluorescein channel. DNA extracted by previously described boiling method [16].

Minimum inhibitory concentrations (MICs) were determined by broth microdilution method [Mueller-Hinton broth (Fluka Analytical, Germany) and $20 \%$ horse serum (Himmedsintez)], or using E-tests (Biomerieux, France). MICs of benzylpenicillin, ampicillin, amoxicillin, cefotaxime, ceftriaxone, meropenem, ciprofloxacin, tetracycline, chloramphenicol, and rifampicin were determined in the range $<0.002->32 \mathrm{mg} / \mathrm{L}$. Strains obtained as part of Microbiology Quality Assessment for $H$. influenzae, $N$. meningitidis, and $S$. pneumoniae identification, susceptibility, and typing (WHO and UK NEQAS, UK) was used as controls.

The results were interpreted using EUCAST breakpoint tables version 8.0 valid from January 1, 2018. $\mathrm{MIC}_{50}$ and $\mathrm{MIC}_{90}$ (antibiotics concentrations inhibiting growth of $50 \%$ and $90 \%$ of the strains, respectively) were determined by ordered array method. Microbiological susceptibility to benzylpenicillin, cefotaxime, ciprofloxacin, and chloramphenicol was determined by comparing MIC values with epidemiological cut-off value (ECOFFV; https://mic.eucast.org/Eucast2/).

Serogenotype of $N$. meningitidis strains was determined by RT-PCR with $\operatorname{syn} D$ (serogroup B), synE (serogroup C), $s a c B$ (serogroup A), $x c b B$ (serogroup X), $\operatorname{syn} G$ (serogroup $\mathrm{W}$ ), and $\operatorname{syn} F$ (serogroup $\mathrm{Y}$ ) genes detection according to WHO and $\mathrm{CDC}$ recommendations [16] and by conventional PCR with $l c b B$ (serogroup L), capZC (serogroup Z), and cap29EH (serogroup E) genes electrophoresis detection in agarose gel [17].

Data entry, statistical processing, and analysis were performed using Microsoft Office version 13.0 software.

\section{Results}

N. meningitidis serogroup distribution

During this study, serogroup distribution of invasive and non-invasive N. meningitidis strains was established (Figure 2).

Invasive and non-invasive $N$. meningitidis strains were presented by different serogroups with dominant serogroup B among invasive strains in $72 \%$ cases $(33 / 46)$ and non-invasive $-53.6 \%(15 / 28)$. Serogroup C distribution was $11 \%$ 


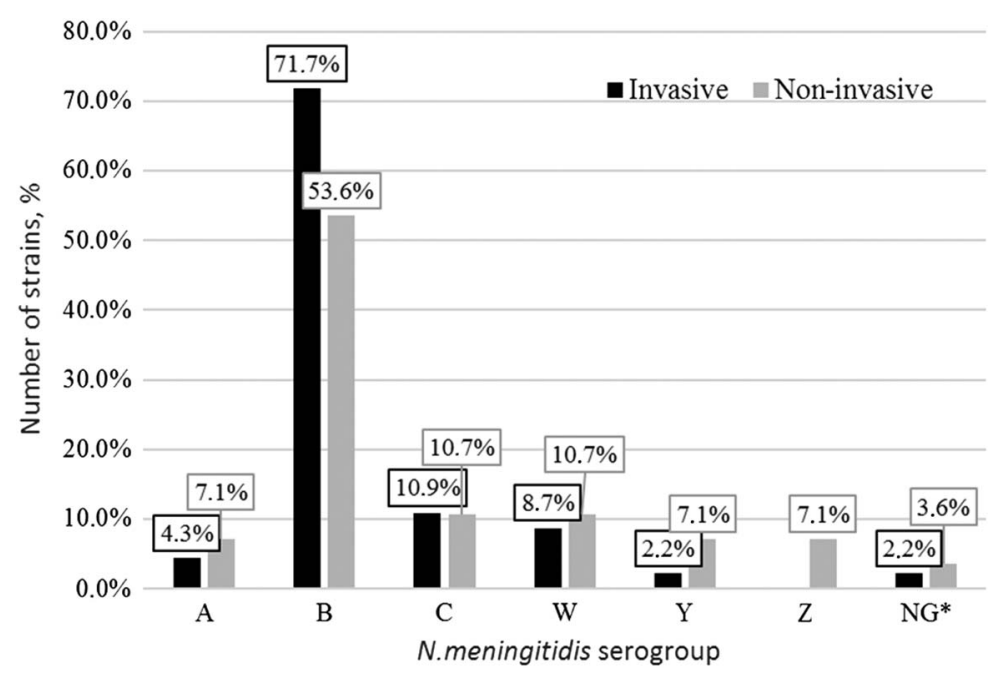

Figure 2. $N$. meningitidis serogroups distribution (\%). Note: *NG marked strains whose serogroup has not been established (not serogroups A, B, C, E, L, W, X, Y, and Z)

(5/46 invasive and 3/28 non-invasive). Serogroups A, W, and Y were also in both groups, but were more common among bacterial carriers. Serogroup $\mathrm{Z}$ was only detected among non-invasive strains $(2 / 28)$. Two strains have not been established as serogroups $\mathrm{A}, \mathrm{B}, \mathrm{C}, \mathrm{E}, \mathrm{L}, \mathrm{W}, \mathrm{X}, \mathrm{Y}$, or $\mathrm{Z}$ and were marked as non-groupable (NG).

N. meningitidis strains susceptibility/resistance to antibiotics

$\mathrm{MIC}_{50}$ and $\mathrm{MIC}_{90}$ of 10 antibiotics and clinical breakpoints (EUCAST 2018, www.eucast.org) are presented in Table I.

As Table I shows, $\mathrm{MIC}_{50}$ for all antibiotics except meropenem was the same among invasive and non-invasive strains and interpreted as susceptible. Meropenem $\mathrm{MIC}_{50}$ for invasive strains was higher than for non-invasive, but both were susceptible. Differences in $\mathrm{MIC}_{90}$ for benzylpenicillin and meropenem were found with higher values among invasive strains.

Antibiotic susceptibility to benzylpenicillin, cefotaxime, ciprofloxacin, and chloramphenicol was determined by comparing MIC values with ECOFFV, which separate bacterial population into susceptible "wild" strains and resistant - strains with acquired resistance mechanisms. This data is used for epidemiological antimicrobial resistance surveillance. 
Table I. $\mathrm{MIC}_{50}$ and $\mathrm{MIC}_{90}$ values of $N$. meningitidis strains

\begin{tabular}{lcccccc}
\hline & \multicolumn{2}{c}{$\mathrm{MIC}_{50}(\mathrm{mg} / \mathrm{L})$} & & \multicolumn{2}{c}{$\mathrm{MIC}_{90}(\mathrm{mg} / \mathrm{L})$} & \\
\cline { 2 - 3 } Antibiotics & $\begin{array}{c}\text { Invasive } \\
(n=46)\end{array}$ & $\begin{array}{c}\text { Non-invasive } \\
(n=28)\end{array}$ & & $\begin{array}{c}\text { Invasive } \\
(n=46)\end{array}$ & $\begin{array}{c}\text { Non-invasive } \\
(n=28)\end{array}$ & $\begin{array}{c}\text { Breakpoints } \\
\text { S/R }(\mathrm{mg} / \mathrm{L})\end{array}$ \\
\hline Benzylpenicillin & 0.032 & 0.032 & & $0.125^{*}$ & $0.064^{*}$ & $\leq 0.06 />0.25$ \\
Ampicillin & 0.032 & 0.032 & & 0.125 & 0.125 & $\leq 0.125 />1$ \\
Amoxicillin & 0.125 & 0.125 & & $0.25^{*}$ & $0.25^{*}$ & $\leq 0.125 />1$ \\
Cefotaxime & 0.016 & 0.016 & & 0.016 & 0.016 & $\leq 0.125 />0.125$ \\
Ceftriaxone & $<0.002$ & $<0.002$ & & 0.016 & 0.016 & $\leq 0.125 />0.125$ \\
Meropenem & 0.008 & 0.004 & & 0.016 & 0.008 & $\leq 0.25 />0.25$ \\
Ciprofloxacin & 0.004 & 0.004 & & 0.008 & 0.008 & $\leq 0.03 />0.03$ \\
Tetracycline & 0.25 & 0.25 & & 0.5 & 0.5 & $\leq 1 />2$ \\
Chloramphenicol & 1 & 1 & & 1 & 1 & $\leq 2 />4$ \\
Rifampicin & 0.016 & 0.016 & & 0.25 & 0.25 & $\leq 0.25 />0.25$ \\
\hline
\end{tabular}

Note: S: susceptible; R: resistant; MIC: minimum inhibitory concentration.

*Marked MICs, interpreted as intermediate.

Phenotypical N. meningitidis strains' characteristics, separated to "wild" population and population with resistance mechanisms, are shown in Table II. All strains are susceptible to benzylpenicillin, ciprofloxacin, and chloramphenicol, but two invasive and one non-invasive strains had cefotaxime MICs that shows acquired resistance mechanisms, but clinically interpreted as susceptible. Epidemiological cut-off points cannot be used to determine local resistance levels because they are calculated using aggregate data of MIC distribution from different sources, geographic areas of the world and periods of time; therefore, they cannot be used to determine local resistance levels.

\section{Benzylpenicillin}

According to clinical protocol for diagnosis and treatment of infectious diseases in adults and children $[14,15]$, benzylpenicillin is the drug of choice for meningococcal infections treatment. Figure 3 shows meningococci susceptibility to different benzylpenicillin concentrations. Determined that more than $87 \%$ of all strains were susceptible to benzylpenicillin, but MICs of more than $60 \%$ strains of both groups were $0.032-0.064 \mathrm{mg} / \mathrm{L}$, which is close to border between clinically susceptible and intermediate susceptible. Among invasive strains, $\mathrm{MIC}_{90}$ is higher than among non-invasive and is interpreted as intermediate (0.125 and $0.064 \mathrm{mg} / \mathrm{L}$, respectively). Among strains with intermediate susceptibility to benzylpenicillin $(n=9)$, the dominant serogroup was B (7/9) and serogroup C was detected too (2/9). 


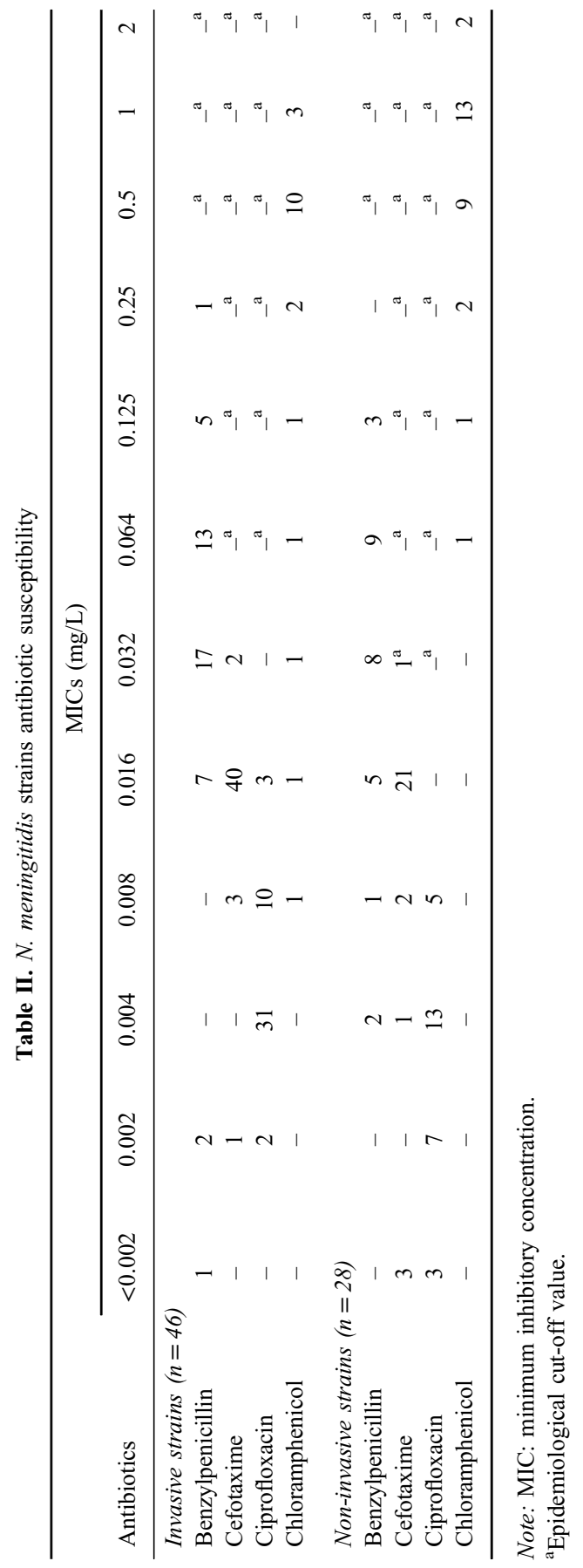




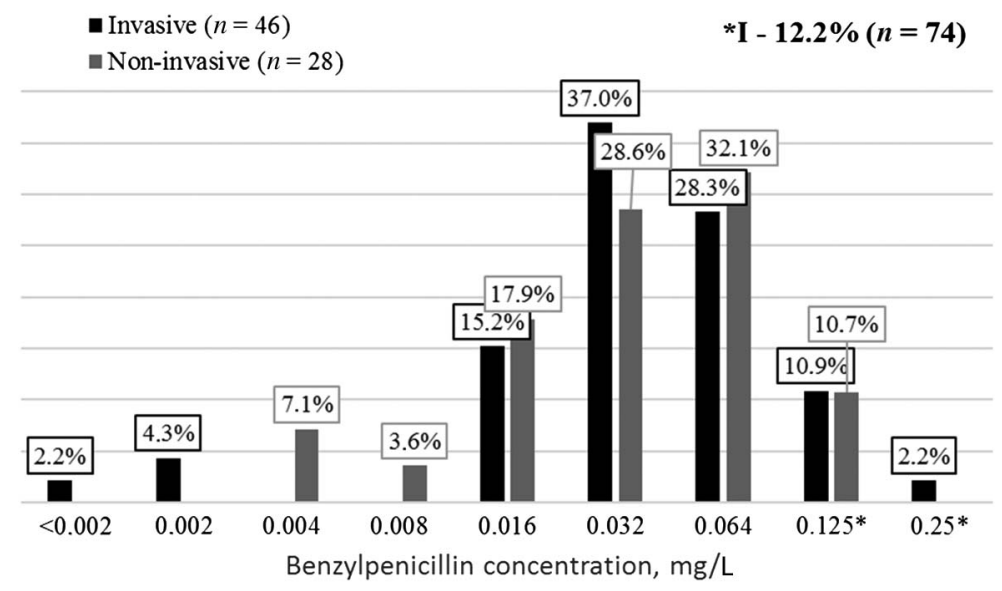

Figure 3. $N$. meningitidis strains susceptibility to benzylpenicillin

\section{Chloramphenicol}

In case of patient's intolerance to $\beta$-lactams, chloramphenicol is used for meningococcal infection treatment $[14,15]$. All $N$. meningitidis strains $(n=74)$ were susceptible to chloramphenicol, but strains with MIC border value $(2 \mathrm{mg} / \mathrm{L})$ were detected $-6.5 \%$ among invasive strains and $7.1 \%$ among non-invasive. All strains with $\mathrm{MIC}=2 \mathrm{mg} / \mathrm{L}$ were $N$. meningitidis serogroup B.

\section{Ampicillin}

Ampicillin is an antibiotic, which is widespread for treating different infectious diseases in hospitals and outpatient department. Figure 4 shows $N$. meningitidis strains susceptibility to different ampicillin concentrations. As seen in Figure 4, the dominant concentration in both groups was $0.032 \mathrm{mg} / \mathrm{L}$ (43.5\% - invasive strains and 35.7\% - non-invasive strains). Determined that $6.8 \%$ of all strains were intermediate susceptible to ampicillin, and among noninvasive strains, the percentage is higher $-10.7 \%$ against $4.3 \%$ among invasive strains. All strains with intermediate susceptibility were N. meningitidis B.

\section{Amoxicillin}

Despite the fact that amoxicillin is not used for meningococcal infections treatment, this antibiotic is widespread for treating different infectious diseases. 


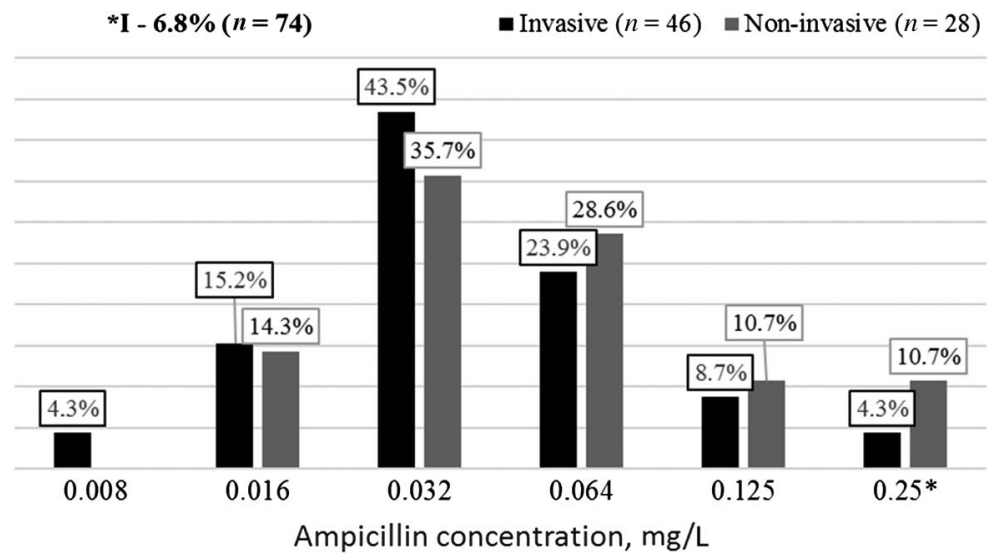

Figure 4. $N$. meningitidis strains susceptibility to ampicillin

Figure 5 shows $N$. meningitidis strains susceptibility to different amoxicillin concentrations. It is noted that $69.6 \%$ of invasive $N$. meningitidis strains and $85.7 \%$ of non-invasive strains were susceptible to amoxicillin. Fourteen strains had intermediate susceptibility. Among 14 invasive strains with intermediate susceptibility, the dominant serogroup is B $(72 \%, 10 / 14)$; serogroups W $(14 \%$, $2 / 14)$, A $(7 \%, 1 / 14)$, and C $(7 \%, 1 / 14)$ were also detected. Almost the same serogroups were detected among four non-invasive strains: serogroup B (2/4), A (1/4), and C (1/4).

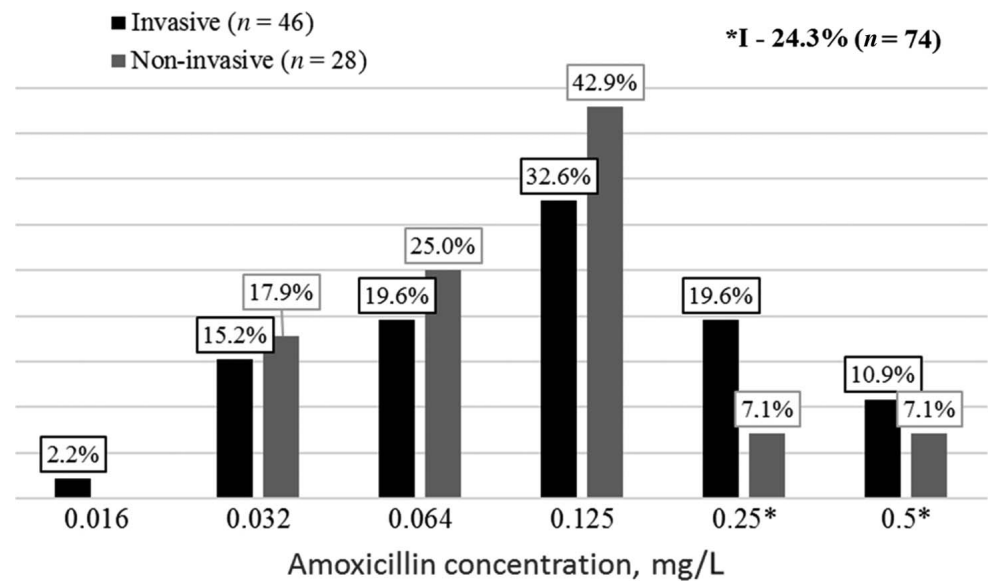

Figure 5. $N$. meningitidis strains susceptibility to amoxicillin 
Third-generation cephalosporines

In accordance with valid clinical protocols, third-generation cephalosporines are used to treat acute meningococcemia and Waterhouse-Friederiksen syndrome in adults [14] and meningococcal meningitis and unspecified meningococcal infection in children [15]. Figure 6 shows $N$. meningitidis strains susceptibility to different cefotaxime and ceftriaxone concentrations. All $N$. meningitidis strains were clinically susceptible to the third-generation cephalosporines. However, two invasive strains (serogroups B and W) and one noninvasive strain (serogroup B) were interpreted as microbiologically resistant to cefotaxime $(\mathrm{MIC}=0.032 \mathrm{mg} / \mathrm{L})$. It means that they probably had acquired resistance mechanisms.

\section{Meropenem}

In accordance with valid clinical protocols, meropenem is also used as reserve antibiotic for treating adults with Waterhouse-Friederiksen syndrome or meningococcal meningitis [14]. In case of ceftriaxone intolerance in children, meropenem is used for treating meningococcal heart disease (A39.5) [15]. Meningococcal strains' resistance level to meropenem is low $-\mathrm{MIC}_{90}$ is 0.016 and $0.008 \mathrm{mg} / \mathrm{L}$ for invasive and non-invasive strains, respectively.

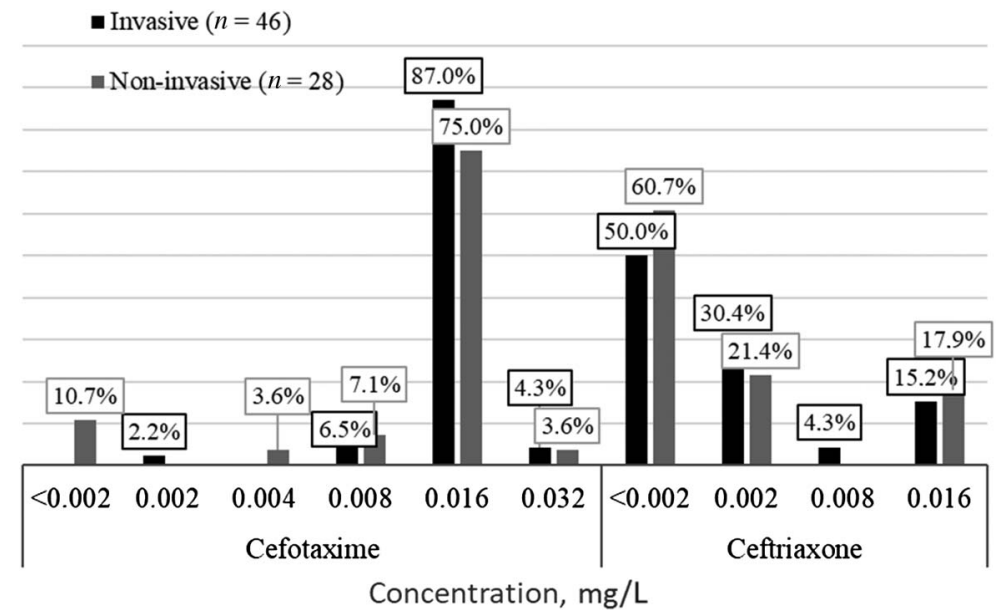

Figure 6. $N$. meningitidis strains susceptibility to third-generation cephalosporines 


\section{Ciprofloxacin}

It was established that all strains were clinically and microbiologically susceptible to ciprofloxacin. For invasive meningococci, $\mathrm{MIC}_{90}$ is higher than for non-invasive strains -0.008 and $0.004 \mathrm{mg} / \mathrm{L}$, respectively. Ciprofloxacin is not used to treat meningococcal infection now, but to prevent secondary infection $[14,15,18]$.

\section{Tetracycline}

All invasive and non-invasive $N$. meningitidis strains $(n=74)$ were clinically susceptible to tetracycline, but strains close to breakpoint concentration $(\mathrm{MIC}=1 \mathrm{mg} / \mathrm{L})$ were also detected $-6.5 \%$ among invasive meningococci and $3.4 \%$ among non-invasive.

\section{Rifampicin}

Rifampicin is known as an anti-tuberculosis drug and not a widespread antibiotic for other infections, but it can be used for meningitis prophylaxis [18]. Figure 7 shows $N$. meningitidis strains susceptibility to different rifampicin concentrations.

Clinically resistant to rifampicin strains were identified among invasive meningococci - 8.7\% (4/46) and non-invasive - 10.7\% (3/28). Among

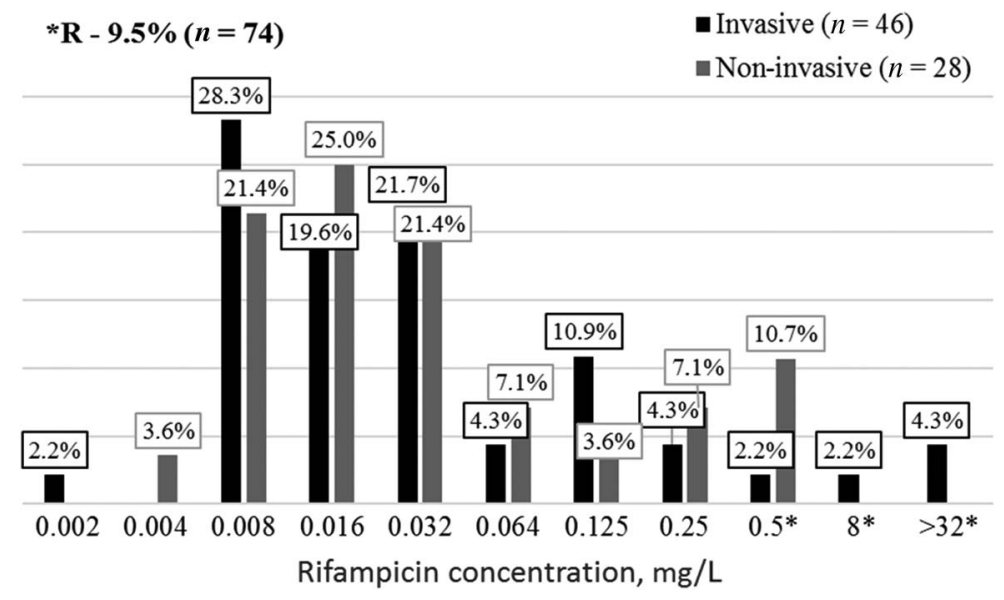

Figure 7. N. meningitidis strains susceptibility to rifampicin 
invasive-resistant meningococci three strains, serogroup B was isolated in Minsk, Iwie (Grodno region) and Pinsk (Brest region). Strain from Pinsk was also intermediate susceptible to amoxicillin. Invasive-resistant $N$. meningitidis strain from Luban (Minsk region) was identified as NG (not A, B, C, E, L, W, X, $\mathrm{Y}$, and $\mathrm{Z}$ ). Among non-invasive strains, resistant meningococci were isolated in Brest - serogroup B, Vitebsk - serogroup B, and Orsha - serogroup Y (Vitebsk region). Strain from Vitebsk was also intermediate susceptible to benzylpenicillin.

\section{Discussion}

Meningococcal infection surveillance is prerequisite for improving the treatment efficiency as well as to prevent spread of infection among carriers and the transition to generalized forms, such as meningitis, meningococcemia, and endocarditis. Meningococcal infection surveillance is currently available in Belarus, but it is needed to be improved first with the expansion of the geographical coverage of the support bases (hospitals and laboratories); second, biomaterial and isolates transfer to reference laboratory; third, relationship between all members of surveillance system improvement. Antimicrobial resistance surveillance in general and $N$. meningitidis antimicrobial resistance surveillance in particular are the obligatory condition of effective infectious control on local, regional, and republican levels [1, 13].

PPhenotypic susceptibility/resistance of invasive and non-invasive meningococci to penicillins (benzylpenicillin, amoxicillin, and ampicillin), third-generation cephalosporines (cefotaxime and ceftriaxone), carbapenems (meropenem), tetracyclines (tetracycline), fluoroquinolones (ciprofloxacin), amphenicols (chloramphenicol), and rifampicins (rifampicin) shows that there are N. meningitidis strains with intermediate susceptibility to penicillins and resistance to rifampicin circulating in Belarus.

In accordance with valid clinical protocols $[14,15]$, benzylpenicillin is still used for meningococcal infection treatment. Among all Belarussian $N$. meningitidis strains, $12.2 \%$ were intermediate susceptible to benzylpenicillin $(\mathrm{MIC}=0.125-0.25 \mathrm{mg} / \mathrm{L})$ with $13 \%$ in invasive meningococci group and $10.7 \%$ in non-invasive group. Strains with intermediate susceptibility to $\beta$-lactams were found in other countries all over the world [5, 12, 19, 20]. In Belgium, e.g., the level of non-susceptible to penicillin isolates was $15.3 \%$ with dominant serogroup B. In Russia, the level of non-susceptibility was decreased from $11 \%$ in 2006-2011 to $2 \%$ in $2012-2015$ [21]. 
The highest level of intermediate susceptibility in $N$. meningitidis strains was to aminopenicillins - to ampicillin (4.3\% among invasive strains and $10.7 \%$ among non-invasive) and amoxicillin (30.4\% invasive and 14.3\% non-invasive), which indicates the widespread use of these antibiotics in clinical and prophylactic practice. However, low meningococci susceptibility to ampicillin was also previously detected in Belarus [13]. The percentage of intermediate susceptible strains decreased from $53 \%$ in 2010 to $6.8 \%$ with the significant decrease of $\mathrm{MIC}_{90}$ value $-0.064 \mathrm{mg} / \mathrm{L}$ in comparison with $>0.25 \mathrm{mg} / \mathrm{L}$ in 2010 .

Serogroup distribution of $N$. meningitidis strains with intermediate susceptibility to penicillins is as follows: serogroup $\mathrm{B}-74.4 \%$, serogroup $\mathrm{C}-10.3 \%$, serogroup $\mathrm{A}$ and $\mathrm{W}-5.1 \%$ each, and other $-5.1 \%$.

The data about unsusceptible to ciprofloxacin isolates in the counties of North America were reported $[9,10]$. However, all the studied Belarusian $N$. meningitidis strains were susceptible to this antibiotic; $\mathrm{MIC}_{90}$ among invasive and non-invasive strains is $0.008 \mathrm{mg} / \mathrm{L}$.

During this study, $9.5 \%$ of $N$. meningitidis strains were resistant to rifampicin (MIC > $0.25 \mathrm{mg} / \mathrm{L}$ ): $8.7 \%$ among invasive meningococci and $10.7 \%$ among non-invasive. There are publications about rifampicin-resistant meningococci in European countries (Hungary, Germany, France, and Switzerland) [4, 7, 21], in America (Canada, USA, Uruguay, and Brazil) [5, 9], and in Australia [7]. In Moscow, resistant meningococci serogroup B were also detected [22]. Previously, resistant to rifampicin meningococci has not been described in Belarus [13]; however, the $\mathrm{MIC}_{50}$ and $\mathrm{MIC}_{90}$ levels have not changed since 2010 and are 0.016 and $0.25 \mathrm{mg} / \mathrm{L}$, respectively.

All studied strains were susceptible to third-generation cephalosporines. However, in comparison with Belarussian data from 2010, $\mathrm{MIC}_{90}$ increased from $0.008 \mathrm{mg} / \mathrm{L}$ in 2010 to $0.016 \mathrm{mg} / \mathrm{L}$ for both cefotaxime and ceftriaxone [13]. On the other hand, $\mathrm{MIC}_{50}$ and $\mathrm{MIC}_{90}$ to meropenem significantly decreased. Thus, $\mathrm{MIC}_{90}$ to meropenem $>0.03 \mathrm{mg} / \mathrm{L}$ in 2010 decreased to $0.016 \mathrm{mg} / \mathrm{L}$ among invasive $N$. meningitidis strains and to $0.008 \mathrm{mg} / \mathrm{L}$ among non-invasive [13].

In this study, no unsusceptible to chloramphenicol N. meningitidis strains were detected in Belarus $\left(\mathrm{MIC}_{90}=1 \mathrm{mg} / \mathrm{L}\right)$; whereas the level intermediate susceptible strains were $54 \%$ earlier [13], so there is a decrease of such isolates circulation.

Thus, among antibiotics that are used for meningococcal infection treatment, N. meningitidis strains are strongly susceptible to chloramphenicol $\left(\mathrm{MIC}_{90}=\right.$ $1 \mathrm{mg} / \mathrm{L})$, ceftriaxone $\left(\mathrm{MIC}_{90}=0.016 \mathrm{mg} / \mathrm{L}\right)$, meropenem $\left(\mathrm{MIC}_{90}=0.016 \mathrm{mg} / \mathrm{L}\right.$ among invasive strains and $\mathrm{MIC}_{90}=0.008 \mathrm{mg} / \mathrm{L}$ among non-invasive), and 
benzylpenicillin $\left(\mathrm{MIC}_{90}=0.064 \mathrm{mg} / \mathrm{L}\right.$ among non-invasive), whereas invasive strains were intermediate susceptible to benzylpenicillin $\left(\mathrm{MIC}_{90}=0.125 \mathrm{mg} / \mathrm{L}\right)$.

Among antibiotics that are used for meningococci elimination in carriers, ciprofloxacin was clinically high susceptible in vitro $\left(\mathrm{MIC}_{90}=0.008 \mathrm{mg} / \mathrm{L}\right)$, whereas resistant to rifampicin strains was detected; hence $\mathrm{MIC}_{90}$ is higher.

Antibiotic resistance surveillance must be the part of meningococcal infection surveillance as the reasonable and scientifically based element of meningococcal infection treatment and prevention improvement. Molecular surveillance as a part of meningococcal infection surveillance is also needed, especially after antimeningococcal vaccination introduction.

\section{Conflict of Interest}

The authors declare no conflict of interests regarding the publication of this paper.

\section{References}

1. Titov, L. P.: Meningococcal infection: Current state of problem. Healthcare (Belarus) [Zdravookhranenie] 12, 15-23 (2010) (in Russian).

2. On the establishment of the Republican Reference Laboratory for the Diagnosis of Invasive Bacterial Diseases: Order of the Ministry of Health of the Republic of Belarus of March 25, 2013. 379, 1-9 (2013) (in Russian).

3. On the implementation of Sentinel Surveillance for Invasive Bacterial Diseases in the Republic of Belarus: Order of the Ministry of Health of the Republic of Belarus of September 20, 2012, 1102, 1-8 (2012) (in Russian).

4. Toth, A., Berta, B., Tirczka, T., Jekkel, C., Abraham, A., Prohaszka, Z., Bognar, Z., Erdosi, T.: First description of a rifampicin-resistant Neisseria meningitidis serogroup $Y$ strain causing recurrent invasive meningococcal disease in Hungary. Acta Microbiol Immunol Hung 64, 1-7 (2017).

5. Bertrand, S., Carion, F., Wintjens, R., Mathys, V., Vanhoof, R.: Evolutionary changes in antimicrobial resistance of invasive Neisseria meningitidis isolates in Belgium from 2000 to 2010: Increasing prevalence of penicillin nonsusceptibility. Antimicrob Agents Chemother 56, 2268-2272 (2012).

6. Skoczyńska, A, Wa ko, I., Kuch, A., Kadłubowski, M., Goł biewska, A., Fory, M., Markowska, M., Ronkiewicz, P., Wasiak, K., Kozińska, A., Matynia, B., Hryniewicz, W.: A decade of invasive meningococcal disease surveillance in Poland. PLoS One 8, e71943 (2013).

7. Delaune, D., Andriamanantena, D., Mérens, A., Viant, E., Aoun, O., Ceppa, F., Taha, M. K., Rapp, C.: Management of a rifampicin-resistant meningococcal infection in a teenager. Infection 41, 705-708 (2013).

8. Gorla, M. C., de Paiva, M. V., Salgueiro, V. C., Lemos, A. P., Brandão, A. P., Vázquez, J. A., Brandileone, M. C.: Antimicrobial susceptibility of Neisseria meningitidis strains 
isolated from meningitis cases in Brazil from 2006 to 2008. Enferm Infecc Microbiol Clin 29, 85-89 (2011).

9. Tsang, R. S., Law, D. K., Deng, S., Hoang, L.: Ciprofloxacin-resistant Neisseria meningitidis in Canada: Likely imported strains. Can J Microbiol 63, 265-268 (2017).

10. Harcourt, B. H., Anderson, R. D., Wu, H. M., Cohn, A. C., MacNeil, J. R., Taylor, T. H., Wang, X., Clark, T. A., Messonnier, N. E., Mayer, L. W.: Population-based surveillance of Neisseria meningitidis antimicrobial resistance in the United States. Open Forum Infect Dis 2, 117 (2015).

11. Peak, I. R., Jennings, C. D., Jen, F. E., Jennings, M. P.: Role of Neisseria meningitidis PorA and PorB expression in antimicrobial susceptibility. Antimicrob Agents Chemother 58, 614-616 (2014).

12. Tripathi, V., Tripathi, P., Srivastava, N., Gupta, D.: In silico analysis of different generation $\beta$ lactams antibiotics with penicillin binding protein-2 of Neisseria meningitidis for curing meningococcal disease. Interdiscip Sci 6, 259-270 (2014).

13. Glazkova, S. E., Lebedev, F. A., Titov, L. P.: Neisseria meningitidis strains sensitivity to antibiotics. Healthcare (Belarus) [Zdravookhranenie] 10, 26-31 (2011) (in Russian).

14. Clinical protocols for the diagnosis and treatment of the adult population with infectious and parasitic diseases: Appendix 5 to the order of the Ministry of Health of the Republic of Belarus of June 13, 2006. 484, 271-442 (2006) (in Russian).

15. On approval of the clinical protocol and declaring as invalid a separate structural element of the order of the Ministry of Health of the Republic of Belarus of June 13, 2006 No. 484: Order of the Ministry of Health of the Republic of Belarus of August 24, 2012. 961, 1-138 (2006) (in Russian).

16. World Health Organization \& Centers for Disease Control and Prevention (U.S.): Laboratory methods for the diagnosis of meningitis caused by Neisseria meningitidis, Streptococcus pneumoniae, and Haemophilus influenza: WHO manual, WHO/IVB.11.09, $2^{\text {nd }}$ Edition. World Health Organization, Geneva, 2011, p. 311. Available at http://www.who. int/iris/handle/10665/70765

17. Zhu, H., Wang, Q., Wen, L., Xu, J., Shao, Z., Chen, M., Chen, M., Reeves, P. R., Cao, B., Wang, L.: Development of a multiplex PCR assay for detection and genogrouping of Neisseria meningitidis. J Clin Microbiol 50, 46-51 (2012).

18. European Committee on Antimicrobial Susceptibility Testing, European Society of Microbiology and Infectious Diseases: Breakpoint tables for interpretation of MICs and zone diameters. Version 8.1, 2018. Available at http://www.eucast.org/clinical_breakpoints

19. Olesky, M., Zhao, S., Rosenberg, R. L., Nicholas, R. A.: Porin-mediated antibiotic resistance in Neisseria gonorrhoeae: Ion, solute and antibiotic permeation through PIB proteins with penB mutations. J Bacteriol 188, 2300-2308 (2006).

20. Tzeng, Y. L., Stephens, D. S.: Antimicrobial peptide resistance in Neisseria meningitides. Biochim Biophys Acta 1848, 3026-3031 (2015).

21. Mounchetrou Njoya, I., Deghmane, A. E., Taha, M. K., Isnard, H., Parent du Châtelet, I.: A cluster of meningococcal disease caused by rifampicin-resistant $\mathrm{C}$ meningococci in France, April 2012. Euro Surveill 17, 20254 (2012).

22. Koroleva, M. A., Koroleva, I. S., Zakroeva, I. M., Gruber, I. M.: The susceptibility of meningococci to the antimicrobial agents in Moscow, 2006-2015. Epidemiol Vaccinal Prev [Ėpidemiologiâ i vakcinoprofilaktika] 88, 7-14 (2016) (in Russian). 